\title{
Tracking and assessing practical chemistry skills development: practical skills portfolios
}

\author{
James S. Wright,, ${ }^{1,2}$ David Read $^{*, 3}$, Oliver Hughes ${ }^{3}$ and Julie Hyde H,1 $^{*, 1}$ \\ ${ }^{1}$ Department of Chemistry, University of Sheffield, Brook Hill, Sheffield S3 7HF (UK). \\ ${ }^{2}$ Guangdong Technion Israel Institute of Technology, Shantou, Guangdong 515063 (PR China) \\ ${ }^{3}$ School of Chemistry and Centre for Higher Education Practice, University of Southampton, \\ Highfield, Southampton SO17 1BJ (UK)
}

Corresponding Authors: julie.hyde@sheffield.ac.uk \& d.read@soton.ac.uk

Keywords: China; Chemistry; Laboratory; Assessment; Reflection

\begin{abstract}
We present the evaluation of the student response to a novel form of practical assessment: the Practical Skills Portfolio (PSP). The PSP is a concise record of a practical activity for the purposes of assessment, which prompts students to engage in reflective practice on laboratory skills, and provides opportunities for enhanced feedback delivered in a timely manner. Key goals of this new approach are to assist students in assimilating the practical skills they are developing during their studies and to support them in developing their ability to write the different components of a full laboratory report.
\end{abstract}

\section{Introduction}

The development of skills and attributes in chemistry has received increasing attention in recent years (Overton \& Garvey, 2017). With regard to practical skills development, this is reflected in recent changes to the " $A$ " Level structure (Read \& Barnes 2015; Barnes, Laham \& Read 2017), the requirements for RSC accreditation of degree programmes (to complete a certain amount of practical work), and the demonstration of skills competence in vocational qualifications. Explicitly assessing and acknowledging the development of students' practical skills should form an integral part of this process, given the role of such skills development in enhancing the employability of science graduates.

Perhaps the most widely used form of assessment in practical Chemistry courses is the post-laboratory write-up, where a script or scientific report is completed by the student. This is, of course, important. Students need to write scientific reports to develop their scientific language skill, and directly assessing their work during a large laboratory class is logistically difficult. While postlaboratory reports can, if carefully designed ('constructively aligned', Biggs (2003)), test the students' understanding of in-laboratory tasks (Johnstone et. al. 1998, Reid \& Shah 2006), they do not necessarily assess the development of practical skill, even though the development of practical skills is arguably one of the main aims of such courses. How can we track or assess the practical skills development of Chemistry students on a large scale, in a logistically feasible manner? This issue is being addressed at " $A$ " Level through the introduction of the new 'practical endorsement' (OFQUAL, 2016), and a number of universities are currently updating their practical courses in a similar way (Brazil 2017). 
Formative assessment of skills development in practical Chemistry has been previously described by Towns et. al. (2015) (see also Hensiek et. al. 2016), and later Seery (2017), through digital badging. Students are videorecorded performing a key task, and are awarded a badge via the virtual learning environment (VLE) to certify their competence. In Seery's modification, students are also exposed to pre-lab videos, which they peer-review, as well as answering a number of questions about the work they are doing in the video. This formative assessment was shown to quantitatively improve students' confidence and experience in selected practical skills.

The applications of digital badging described by Seery, Towns, and Hensiek thus far have been limited to a limited range of techniques: pipetting; preparation of standard solutions; titration and distillation. To assess the skills developed over an entire introductory practical Chemistry course would necessitate significant post-laboratory review on the part of the instructor watching the students' recorded video, which may prove challenging in terms of workload.

\section{Context}

\section{University of Southampton}

The Science Foundation Year at the University of Southampton provides an entry route onto science degree programmes for students who do not have the required qualifications for direct entry. Students complete 10 chemistry practicals over the course of the year, introducing all of the skills commonly encountered by "A" Level chemistry students.

\section{University of Sheffield (Nanjing Tech University (NJTech) Joint Degree) - Practical Skills Portfolio (PSP)}

The University of Sheffield-Nanjing Tech University Degree is a [3+1] joint programme, which began in 2011. It is delivered in English only and is RSC accredited. Students study for three years in Nanjing, China, followed by a year spent in Sheffield, totally integrated with the final-year BSc cohort (Hyde 2014a;b, Hyde et. al. 2016). These students take an abridged, specially designed practical
Chemistry course for their first three years, taught by "flying faculty" UK staff travelling out to Nanjing. This course consists of 17 experiments, designed and selected to develop a practical skill set from a roughly UK "A" level equivalent (in year 1 ), up to a UK second-year degree equivalent level (in years 2 and 3 ).

These are all English as Second Language (ESL) students; who in some cases do not have any significant practical Chemistry experience from High School. (Not all students had the opportunity to study Chemistry in their final years of High School, and indeed those that did, may have had limited practical Chemistry experience.) Therefore, a particular emphasis on building practical skills will be important for any university level course they take. Reflection after the initial delivery of the course suggested that further formative assessment tools to gauge students' development in scientific writing and practical skills development, beyond the post-laboratory report, were necessary in this abridged course.

Links with the University of Southampton, and discussions in 2014 about the Southampton skills assessments led to the PSP model being adapted for use in this unique setting in China. In particular, such a portfolio would be useful for Chinese students in not only developing practical skills but also their chemical language.

\section{Format, delivery and assessment of PSPs}

PSPs were first implemented at Southampton during the 2013/14 academic year and on Sheffield's course in China in 2014/15, with small modifications to templates being implemented each year to enhance the impact on learning. A pro-forma is provided to students which they populate with photographs, reflections and other text or diagrams as required by the tasks set. The PSP pro-formas are generally divided into sections based on 'technique', 'observation' and 'apparatus'. They contain: prompts for students to photograph apparatus and key changes; simple yes/no questions to check understanding; 5-point 'confidence' scales to 
gauge experience; and free-text questions based on common difficulties encountered with new techniques.

At Southampton, students submit PSPs online via Turnitin to be marked electronically, with the aim of returning marks and feedback to students within one week of submission i.e. before the following chemistry practical. An example of a student's submission, with feedback added using Turnitin, is shown in Figure 1a.

In the case of Sheffield, PSPs were initially submitted in paper form, with students completing them in the laboratory, printing photos taken on their smartphones and attaching them to the pro-forma. An example of a student's submission in this format is shown in Figure 1b. PSPs were then checked by a laboratory teacher and returned to students, with written feedback. A collection of pro-formas constituted a physical 'portfolio', evidencing the acquisition of new skills and covering all the practical requirements for students to join and be fully integrated in the Level 3 course in Sheffield. However, discussion with students about this approach at NJTech suggested that, although they understood the purpose of the paper-based Practical Skills Portfolio, students would prefer to submit portfolios online. Therefore, from 2016-17 the Practical Skills Portfolio proformas were instead submitted via Moodle, removing some logistical challenges for students (e.g. printing photos) and for staff (e.g. facilitating assessment and feedback provision in a more constructive manner). Feedback from 2016-17 onward was provided orally in workshop-style classes alongside oral and written feedback on their post-lab written assignments, as an older version of Moodle was in use at Nanjing Tech which did not provide a convenient pathway for written feedback.

\begin{tabular}{|c|c|}
\hline Carrying out a gravity filtration & Level of confidence (circle) 1 (low) $2 \quad 3 \quad 4$ (5) high) \\
\hline & $\begin{array}{l}\text { What was difficult about the } \\
\text { technique? What advice would you } \\
\text { give another student to carry it out } \\
\text { correctly? } \\
\text { In order to transfer the majority of your } \\
\text { solution from the beaker to the conical } \\
\text { flask you need to swirl and pour the } \\
\text { solution very quickly into the filter. This } \\
\text { was difficult because I did not want to } \\
\text { spill any of the solution or overfill the } \\
\text { filter, but also needed to aim correctly } \\
\text { into the fluted funnel paper. } \\
\text { I would advise future students carrying } \\
\text { out a gravity filtration to open up their } \\
\text { fluted filter paper slightly, to create a } \\
\text { bigger area to pour their solution into. } \\
\text { Therefore, they should be able to pour } \\
\text { their solution in more accurately and } \\
\text { quickly, and avoid spilling any solution. } \\
\text { This technique should also efRearathe } \\
\text { filter does not overflow. }\end{array}$ \\
\hline Writing a balanced equation & Level of confidence (circle) 1 (low) $2 \quad 3$ (4.) 5 (high) \\
\hline \multicolumn{2}{|c|}{$\begin{array}{l}\text { Write a balanced symbol equation for the reaction between copper (II) oxide and sulfuric } \\
\text { acid (don't include water of crystallisation in the formula of copper sulfate). }\end{array}$} \\
\hline $\mathrm{CuO}$ & (aq) $\longrightarrow \mathrm{CuSO}_{4 \text { (aq) }}+\mathrm{H}_{2} \mathrm{O}_{(\mathrm{l})}$ \\
\hline \multicolumn{2}{|c|}{$\begin{array}{l}\text { Sulfate salts can be prepared by the reaction of dil. sulfuric acid with the metal itself. Write } \\
\text { a balanced symbol equation to show the formation of magnesium sulfate in this way. }\end{array}$} \\
\hline $\mathrm{Mg}_{\mathrm{s}}$ & aq) $\longrightarrow \mathrm{MgSO}_{4}$ (aq) $+\mathrm{H}_{2 \text { (g) }}$ \\
\hline
\end{tabular}

Figure 1a An example of a Southampton student's PSP including feedback added via Turnitin (used with permission). 


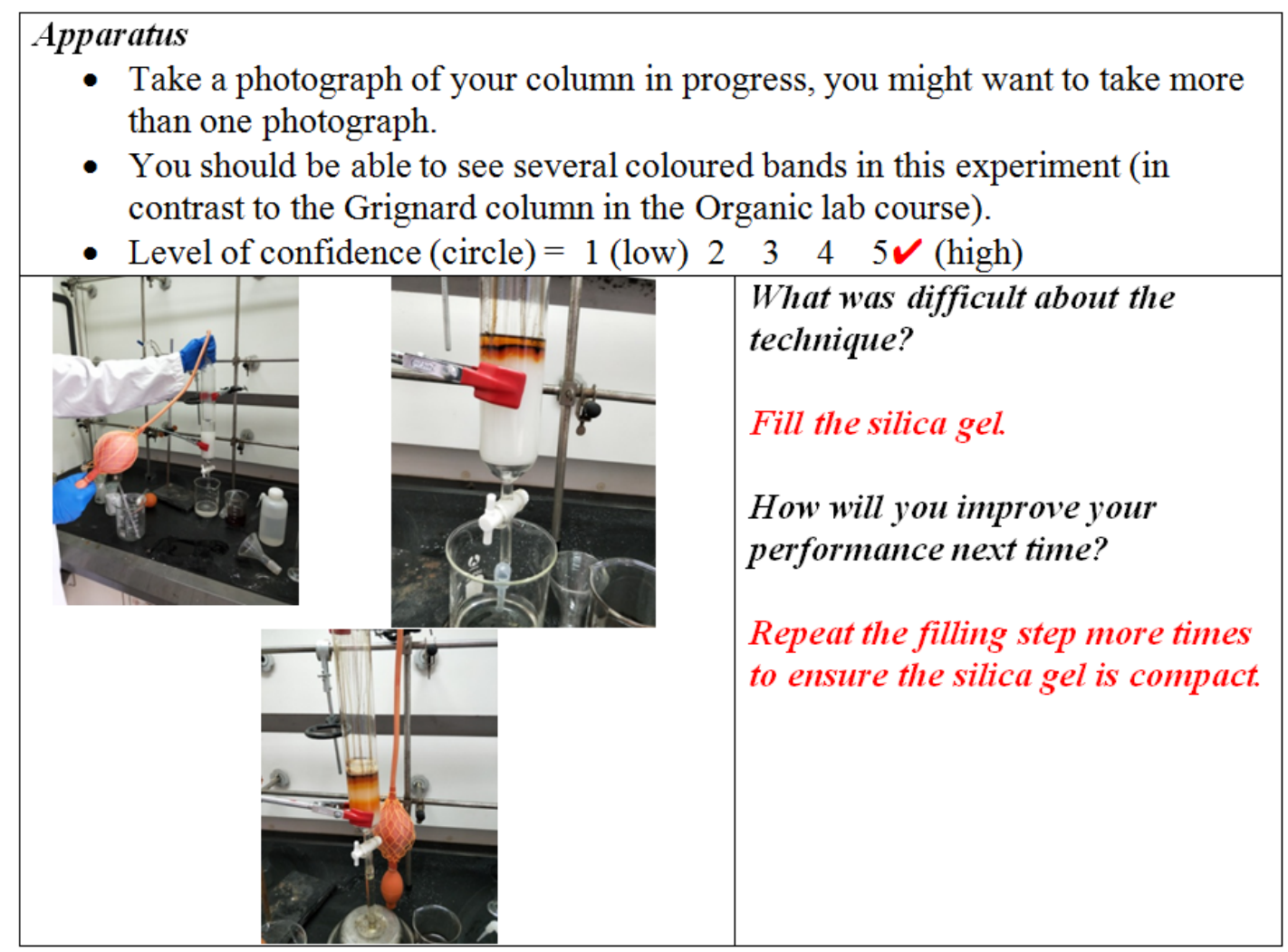

Figure 1b An example 'apparatus' section of a Sheffield-Nanjing student's PSP, submitted via Moodle - oral feedback given in class (used with permission)

\section{The student response to PSPs}

A survey of the 2013/14 cohort of students at Southampton indicated that a majority felt that PSPs improved their understanding of techniques and increased their confidence in undertaking practical work. One noteworthy comment was that:

"Skills portfolios have enabled me to develop my practice. I find it beneficial to record each new skill after the practical and reflect on them at a later date."

Surveys of students on Sheffield's Nanjing programme in 2015/16 and 2016/17 suggested that their attitude to the PSP was generally positive, with a significant majority agreeing with the statement "The Practical Portfolio is helpful for my studies".
In view of the fact that PSPs are designed to help students assimilate practical and report writing skills, it is perhaps more important to consider the longer-term impacts on their progression to more advanced studies. During 2017/18, students who had previously undertaken practical work assessed via PSPs were asked to reflect on the impact of this approach on their subsequent performance, leading to the data presented below. The figures below illustrate students' responses to four different questions on a Likert-type scale, backed up by quotations from students which explain their response. The quotations included were selected on the basis that they provided insight into the student's perceived value of the PSP. 
It had a strong positive impact.

\begin{tabular}{|lll|l|l|}
\hline 6 & & 17 & & 17 \\
\hline & & & & \\
\hline & 18 & & 25 & 11 \\
\hline
\end{tabular}

It had a small positive impact.

It had no impact at all.

\section{1}

It had a small negative impact.

It had a strong negative impact.

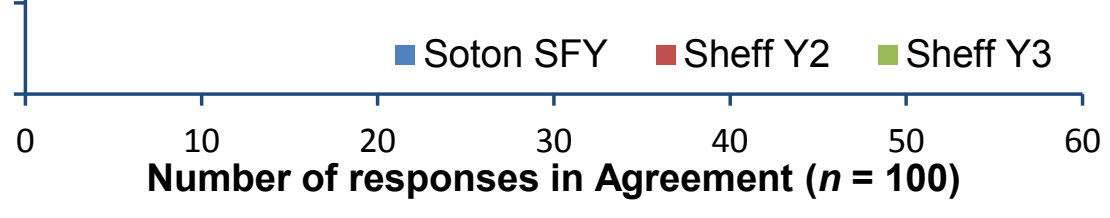

Figure 2 Student responses to the prompt "The skills portfolio required you to collect photographic evidence of you undertaking practical techniques correctly. To what extent did this impact your ability to remember how to perform techniques at a later date?"

The data illustrated in Figure 2 indicates that students have a favourable view of the impact of the photographs in PSPs on their assimilation of practical techniques. This was backed up, anecdotally at least, by staff who noted that students showed greater proficiency when repeating techniques and were less likely to make common errors. Student comments included:

"Going through the techniques I had learned prior to lab work in the first year of my degree and seeing the evidence...gave me confidence."

"Throughout the experiment we had to take pictures of all of nearly all of the steps undertook. This truly helped me remember the steps."

"I never looked back at these photos, but I can remember what I was trying to show to get the perfect photo to my skills portfolio."

"Helpful visual aid for future reference, especially with feedback."

"It created a memory of a skill that was built upon moving forward!"

"I can still remember some techniques about 1 week later, with portfolio it can be much longer."

It had a strong positive impact.

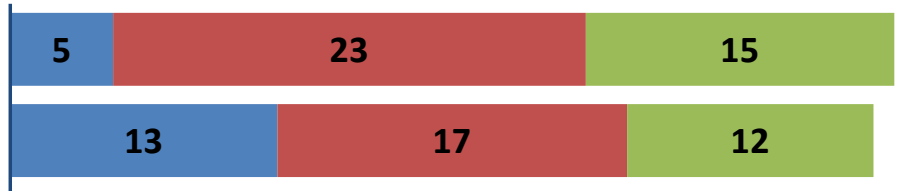

It had no impact at all.

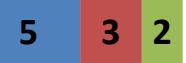

It had a small negative impact.

It had a strong negative impact.

Soton SFY $\backsim$ Sheff Y2 $₫$ Sheff Y3

$\begin{array}{lcccc}0 & 10 & 20 & 30 & 40 \\ & \text { Number of responses in Agreement }(\boldsymbol{n}=\mathbf{9 8})\end{array}$

Figure 3 Student responses to the prompt "To what extent did the use of photographs in the skills portfolio impact on your ability to self-assess and reflect on your performance in carrying out a technique and formulate advice for other students as stipulated in the portfolio?" 
The data illustrated in Figure 3 indicates that students found that the photographs also assisted them in the process of reflecting on their implementation of techniques as required by the PSP. This might help to explain the evidently improved assimilation of techniques exhibited by students. Student comments included:

"I was able to explain any errors in my technique if they had arisen. And (was) able to say where I could improve."
"I think the positive impact came from the comments to those pictures...they allow staff to see the way students perform the experiment while it is impossible to do that in the lab for a large number of students doing the same experiment at the same time."

"the description texts help me more than the pictures but the photographs help to memorise it"

"It reminds me of some procedures during the exam."
It had a strong positive impact.

It had a small positive impact.

It had no impact at all.

It had a small negative impact.

It had a strong negative impact.

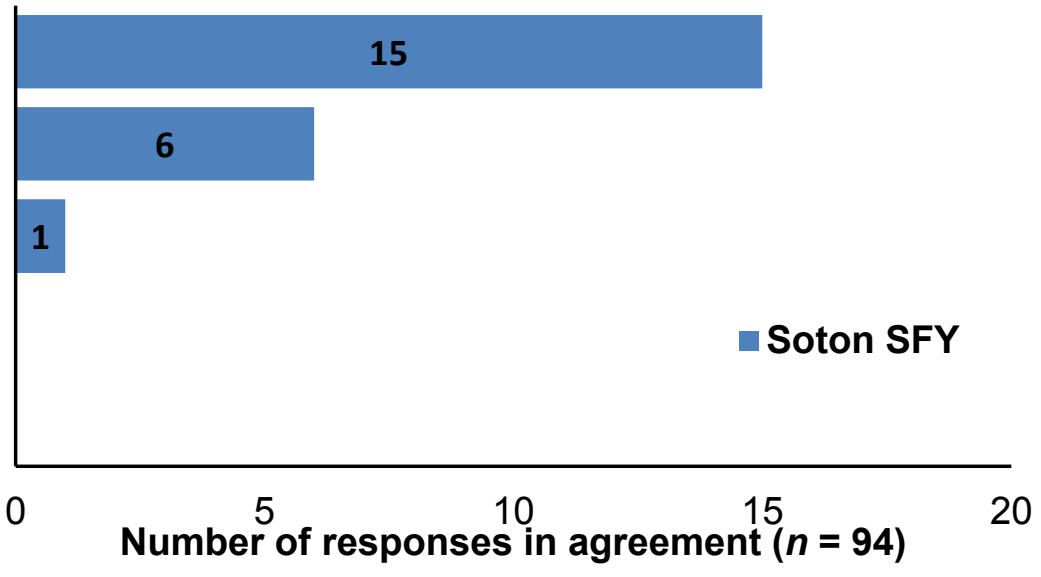

Figure 4 Student responses to the prompt "The skills portfolio gave you the opportunity to practise writing up sections of lab reports after different practicals e.g. a method, an evaluation, or plotting a graph on which you received feedback. To what extent did this impact on your learning compared with writing a full lab report?" (Note that this question was only pertinent to Southampton SFY students)

The data illustrated in Figure 4 indicates that students valued the opportunity to practise writing sections of lab reports and that this had a positive impact on their learning. Student comments included:

"Broke down larger parts of the lab report to easier parts and made labs less intense and more approachable."

"It helped so much as much of the second year (which I am currently completing) involves writing full lab reports. All the guidance and criticism of my foundation year report has helped me go through my work more carefully and lead to high marks in write ups."
"It certainly was beneficial to have the feedback on writing elements of practical report. It helped me to write more concise and accurate reports (as a) result."

"I think it helped to improve skills a little at a time without being overwhelming."
"Report writing is a lot more difficult at this stage, but gave a good base on which to build on and got us using the right skills at an early date." 
It had a strong positive impact.

It had a small positive impact.

It had no impact at all.

It had a small negative impact.

It had a strong negative impact.

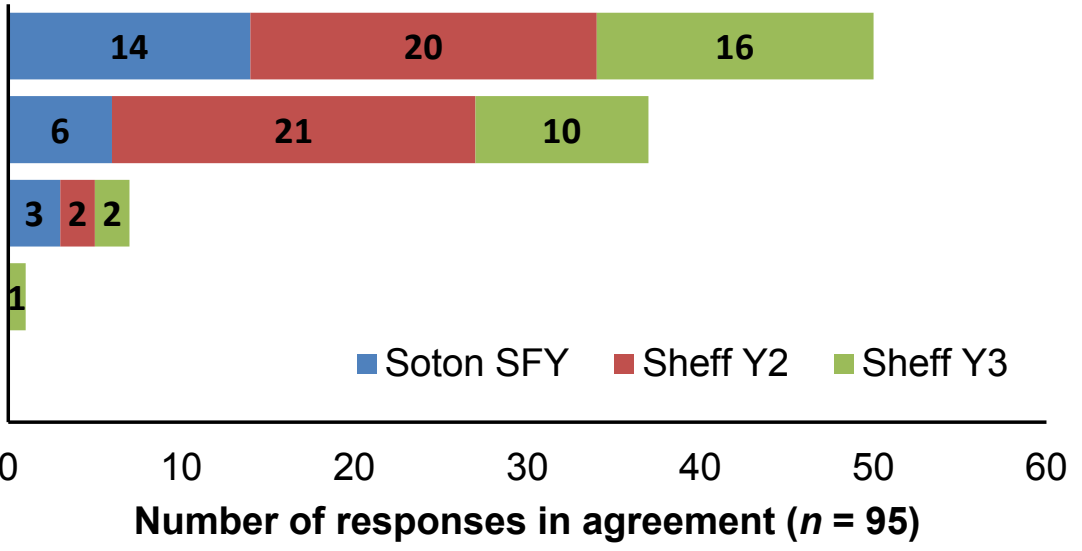

Figure 5: Student responses to the prompt "Since progressing (in your studies), you will have done a lot of practical work. To what extent did the use of skills portfolios (in your earlier studies) impact on your ability to successfully carry out practical work and complete lab reports/write ups?" The prompt for Southampton students referred to progression to degree programmes and the use of PSPs on the foundation year, while that for Sheffield students referred to progression to $Y 2$ or $Y 3$, and the use of PSPs in

China.

The data illustrated in Figure 5 indicates that students have a very positive view of the impact of PSPs in their earlier studies on their ability to perform well in laboratory work. Given the fact that in both cases this was a key aim of the implementation of PSPs, this is a very encouraging outcome. Student comments included:

"I think it gave me confidence to carry out techniques from memory correctly and help others that had not done the foundation year."

"I feel as though I was more prepared to handle the workload and prepare myself better. Having already had some experience of doing write ups meant that I felt more at ease approaching degree level write ups."

"Very grateful to this module - hugely helped with write ups, throughout my degree."

"Knowing how to do certain procedures in the lab as well as calculations in the write up has been a very useful skill that I've had to use every lab so far."

Anecdotally, it appears that Sheffield/Nanjing students' quality of English scientific writing has drastically improved, although this effort has been in tandem with further scientific writing training outside of the laboratory, thus making it difficult to quantify the effect of the PSP on students' scientific writing skills.

\section{Discussion and Conclusions}

The Practical Skills Portfolio (PSP), a novel form of practical skills assessment, has been presented in two forms, used both in the UK (University of Southampton) and China (Nanjing Tech University). Student feedback in response to use of the PSP was very positive: students found that the PSP helped them recall practical techniques, reflect on their performance and prepare for future practical work in later years of study. Students' comments provide strong evidence, albeit based on perception, relating to the features of PSPs that provide value in supporting skills development. In particular, the students' self-reported improvement in their recall of practical techniques is valuable for the Nanjing Tech students, as their Sheffield laboratory course is abridged and runs in only one semester each year. Anecdotally, students preferred the submission of an online PSP, because of the logistical difficulties of printing and reprinting the PSP in Nanjing. 
In summary, PSPs provide a concise approach to the assessment of practical skills and associated activities, reducing workload for students and staff alike and paving the way for success in teaching laboratories at more advanced stages of study.

\section{Future developments}

The use of a GoPro camera to film firstperson perspective laboratory work has been shown by Fung (2015) to enhance pre-lab instructional videos. The Sheffield team are now exploring how a student-worn headmounted Go-Pro can be used to capture the learning of new techniques. A similar method has been used to gather evidence relating to meaningful learning in the laboratory (Galloway \& Bretz, 2015). This studentrecorded footage is already being incorporated into pre-lab instructional videos, and investigation is continuing as to how it can be returned to students for submission as part of the Practical Skills Portfolio in the coming academic year.

At Southampton, the use of a pioneering Laboratory Response system, Labdog, is being trialled for use in the laboratory as an interactive laboratory script which prompts students to answer questions at key points in a practical procedure, facilitating delivery of feedback from staff in real time (Wilson \& Read, 2017). This supports students' reflections on practical work and helps with the completion of PSPs. An evaluation of Labdog will be presented in another article.

\section{Acknowledgements}

An award from the University of Sheffield Deputy Vice President's Learning \& Teaching Fund for the purchase of the GoPro camera is gratefully acknowledged.

The authors also wish to thank the Royal Society of Chemistry and Institute of Physics for facilitation of the annual ViCE/PHEC conferences, which have fostered productive discussions directly contributing to this work.

\section{References}

Barnes, S.M., Laham, A. \& Read, D. (2017) Teachers' views of the impact of the new $A$ level in chemistry. Available at: http://edshare.soton.ac.uk/18928/
Biggs, J. (2003) Teaching for Quality Learning at University - What the Student Does (2nd Edition) SRHE / Open University Press, Buckingham.

Brazil, R. (2017) Curriculums for modern chemists. Education in Chemistry Nov 2017, 22-25.

Fung, F.M. (2015) Using First-Person Perspective Filming Techniques for a Chemistry Laboratory Demonstration To Facilitate a Flipped Pre-Lab. Journal of Chemical Education 92, 1518-1521. DOI: 10.1021/ed5009624.

Galloway, K.R., \& Bretz, S.L. (2016). Video episodes and action cameras in the undergraduate chemistry laboratory: eliciting student perceptions of meaningful learning. Chemistry Education Research and Practice 17(1), 139-155. DOI: 10.1039/c5rp00196j.

Overton, T. \& Garvey, D.J. (2017) Development of key skills and attributes in chemistry. Chemistry Education Research and Practice 18, 401-402. DOI: 10.1039/c7rp90006f.

Hensiek, S., DeKorver B.K., Harwood, C.J., Fish, J., O'Shea, K. \& Towns, M. (2016) Improving and Assessing Student Hands-On Laboratory Skills Through Digital Badging. Journal of Chemical Education 93, 18471854. DOI: $10.1021 /$ acs.jchemed.6b00234.

Hyde J. (2014a) Taking Laboratory Chemistry to China: A Personal View. New Directions in the Teaching of Physical Science 10, 32-35. DOI: 10.29311/ndtps.v0i10.521

Hyde J. (2014b) Can you teach University Chemistry Abroad? Chemistry in Sri Lanka 31, 18-19.

Hyde, J., Cranwell, P. \& Page, E. (2016) Collaborative chemistry degrees. Education in Chemistry June 2016, 22-25.

Johnstone, A.H., Watt, A.T. \& Zaman, T.U. (1998) The students' attitude and cognition change to a physics laboratory. Physics Education 33, 22-29. DOI: 10.1088/00319120/33/1/016. 
OFQUAL (2016) GCE Subject Level Conditions and Requirements for Science (Biology, Chemistry, Physics) and Certificate Requirements. Available at: https://www.gov.uk/government/publications/g ce-subject-level-conditions-and-requirementsfor-science

Read, D. \& Barnes, S.M. (2015) Review of Alevel content. Available at: http://edshare.soton.ac.uk/14806/

Reid, N. \& Shah, I. (2006) The role of laboratory work in university chemistry. Chemistry Education Research and Practice 8, 172-185. DOI: 10.1039/b5rp90026c.

Seery, M.K., Agustian, H.Y., Doidge, E.D., Kucharski, M.M., O'Connor, H.M. \& Price, A.
(2017) Developing laboratory skills by incorporating peer-review and digital badges. Chemistry Education Research and Practice 18, 403-419. DOI: 10.1039/c7rp00003k.

Towns M., Harwood M.J., Robertshaw, M.B., Fish, J. \& O'Shea, K. (2015) The Digital Pipetting Badge: A Method To Improve Student Hands-On Laboratory Skills. Journal of Chemical Education 92, 2038-2044. DOI: 10.1021/acs.jchemed.5b00464.

Wilson, T., \& Read, D. (2017). Learning from Labdog: Best Practice for Laboratory Response System Questions. In Conference Proceedings. New Perspectives in Science Education (p. 299). libreriauniversitaria. it Edizioni. 